\title{
Hybrid Reluctance Machines with U-Shaped Electromagnets and Permanent Magnets
}

\author{
P.Andrada ${ }^{1}$, B. Blanque ${ }^{1}$, E. Martinez ${ }^{1}$, M.Torrent $^{1}$, O. Rolando Ávila ${ }^{2}$, M. Gomila ${ }^{1}$, X. Adelantado ${ }^{2}$ \\ ${ }^{1}$ GAECE, EPS d'Enginyeria de Vilanova i la Geltrú, Departament d'Enginyeria Elèctrica \\ Universitat Politècnica de Catalunya (UPC) \\ Av. Victor Balaguer 1, 08800 Vilanova i la Geltrú, Spain \\ Phone number:+34 938967732, e-mail: pere.andrada@upc.edu \\ ${ }^{2}$ RAC Technologies S.A., Sucre Bolivia
}

\begin{abstract}
This paper is about hybrid reluctance machines, in which the stator or fixed part has a combination of U-shaped electromagnets with permanents magnets placed between their arms while the moving part is simply a structure with salient poles. They can be designed to build different types of rotary or linear electric motors and generators with outstanding performances. In this paper, first, the principle of operation of these machines is explained. Then different types of hybrid reluctance machines using this particular structural configuration are described showing their potential based on simulations and experimental results.
\end{abstract}

\section{Key words}

Electric machines, motor, generator, hybrid reluctance machines, electronic power converters.

\section{Introduction}

Hybrid reluctance machines are an alternative to meet the objectives of modern drives as high efficiency and high torque mass ratio. They can be also an interesting option in some applications of distributed generation. They combine the best of switched reluctance machines (simplicity constructive of the rotor) with the best of the brushless DC motors and/or the synchronous permanent magnet machines (high torque/power density) [1-2].

This paper deals with hybrid reluctance machines, which are based on the combination of some previously known technical contributions as:

- The use of short magnetic circuits in the stator phases, being magnetically isolated between them, which had already been used in switched reluctance motors [3-4].

- The use of electromagnets with permanent magnets which were first reported by Garron [5] and then by Bailey et al. [6] in their magnetic polarized device.

Up to date very little has been published on the utilization of these contributions to the HRMs except Rolando Avila that proposed a multilayer or multistack hybrid reluctance motor based on the use of the electromagnet with permanent magnets [7] and Nakamura et al. that studied a novel switched reluctance motor with the magnets placed between the stator poles tips [8].

The operating principle of the electromagnet with permanent magnet is shown in Fig. 1. The electromagnet is U-shaped with a magnet placed between the extremes of their arms. When no current flows through the coil the flux created by the magnet is closed through the yoke of the $\mathrm{U}$ core and does not cross the air gap as it is seen in Fig. 1A. But, when a current flows through the coil the flux of the magnet is added to the flux generated by the action of the coil, see Fig. 1 B, which originates an electromagnetic attraction force superior to that produced by a $U$ core without the permanent magnet. Obviously, the permanent magnet has to be magnetized in such a way that its flux adds to the flux created by the energized coils.

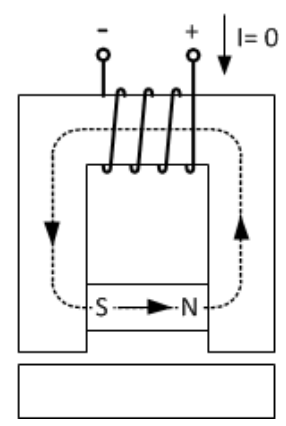

(A)

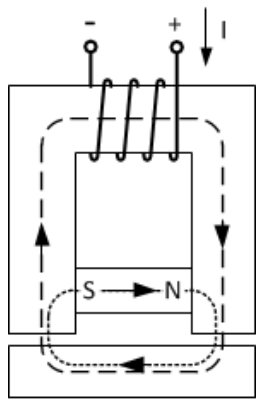

(B)
Fig. 1. Electromagnet with permanent magnet. (A) Flux distribution without current through the coil. (B) Flux distribution with current through the coil.

The stator or fixed part of hybrid reluctance machines, motors and generators, can be built using the combination of several electromagnets with permanent magnets while the moving part is a simple structure with salient poles. Thus different types of hybrid reluctance machines can be constructed [9]:

- Single-layer rotary hybrid reluctance machines, 
with the phases in a single layer in the same plane.

- Multilayer or multistack rotary hybrid reluctance machines, with the phases arranged in different parallel planes.

- Linear hybrid reluctance machines.

The hybrid reluctance machine has to be controlled, in any case, by an electronic power converter in which the switching sequence of the phases is generated according to the rotor position determined by a speed-position transducer or estimated by means of the voltages and currents of the motor. Usually, the electronic power converter is an asymmetric half bridge, as those used by switched reluctance motor drive; see Fig. 2. It is controlled using PWM or hysteresis control for low speed and single pulse control for high speeds.

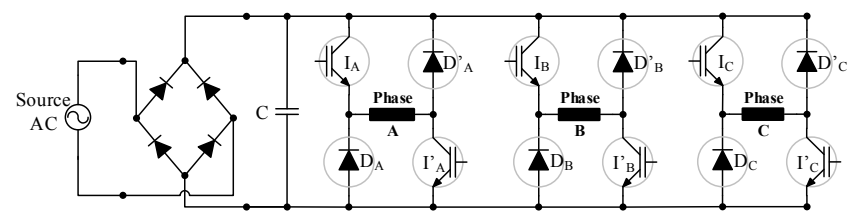

Fig. 2. Electronic power converter, asymmetric half bridge.

\section{Single Layer Rotary Hybrid Reluctance Machines}

\section{A. Single layer rotary hybrid reluctance motor}

In single layer rotary hybrid reluctance motor the stator consists of $\mathrm{N}_{\mathrm{p}}$ electromagnets with permanent magnets, each one or combinations of such (with $\mathrm{k}$ multiplicity) constitute one phase of the motor where $\mathrm{m}$ is the number of phases. The rotor is formed by $\mathrm{N}_{\mathrm{R}}$ salient poles. The stator, with $\mathrm{N}_{\mathrm{S}}$ poles, has to be designed in such a way that for each phase there is a position of alignment of the stator poles with the rotor poles and the electromagnets with permanent magnets have to be placed according to Fig. 4. Therefore, the following rules have to be considered:

$$
\begin{gathered}
N_{p}=k \cdot m(1) \\
N_{s}=2 \cdot k \cdot m(2) \\
N_{R}=k \cdot(2 m-1)(3)
\end{gathered}
$$

The angle, $\gamma$, between two consecutive electromagnets with permanent magnets is given by:

$$
\gamma=\frac{360^{\circ}}{N_{P}}(4)
$$

And the angle, $\alpha$, between two rotor poles is equal to:

$$
\alpha=\frac{360^{\circ}}{N_{R}}(5)
$$

Therefore the angle, $\delta$, between the stator poles of two consecutive electromagnets with permanent magnets is:

$$
\delta=\gamma-\alpha=\frac{360^{\circ} \cdot\left(N_{R}-(k \cdot m)\right)}{k \cdot m \cdot N_{R}}
$$

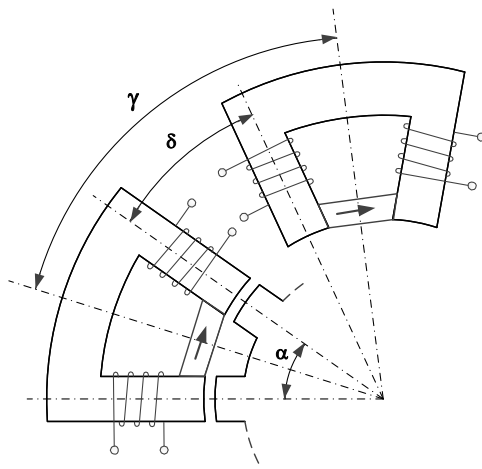

Fig. 3. Disposition of the electromagnets with permanent magnets in the single layer rotary hybrid reluctance machine.

The simplest configuration of the three-phase single layer hybrid reluctance motor with three electromagnets and five pole rotor poles has been studied [10-11]. The main parameters of the proposed motor are listed in Table $\mathrm{I}$, the nominal speed is fixed at $3000 \mathrm{rpm}$ and the motor embedded in a frame IEC 80. A perspective view of this motor is shown in Fig. 4. Due to this particular construction, which ensures a better use of materials, this motor has in addition short magnetic circuits, independence of phases what it means lower iron losses and fault tolerance, and has no cogging torque.

Table I. Main parameters of the proposed single layer rotary hybrid reluctance machine.

\begin{tabular}{|c|c|c|c|c|c|c|c|}
\hline $\mathrm{k}$ & $\mathrm{m}$ & $\mathrm{N}_{\mathrm{P}}$ & $\mathrm{N}_{\mathrm{S}}$ & $\mathrm{N}_{\mathrm{R}}$ & $\alpha$ & $\gamma$ & $\delta$ \\
\hline 1 & 3 & 3 & 6 & 5 & $72^{\circ}$ & $120^{\circ}$ & $48^{\circ}$ \\
\hline
\end{tabular}

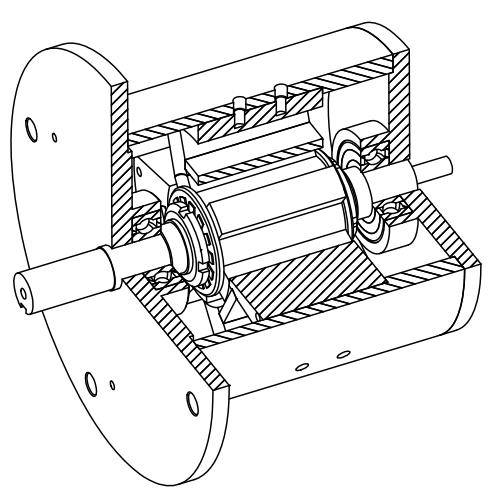

Fig. 4. Perspective view of the proposed single layer rotary hybrid reluctance machine.

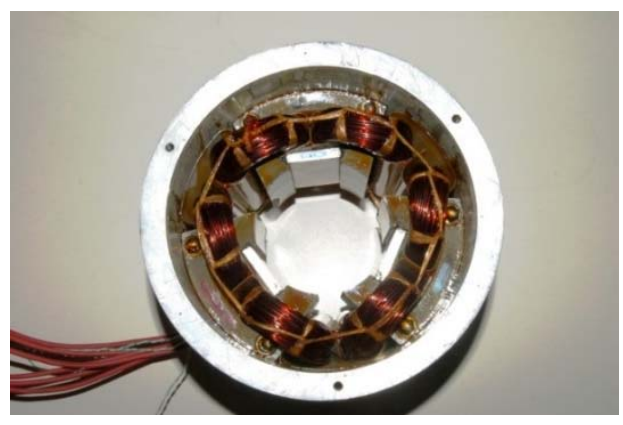

(A) 


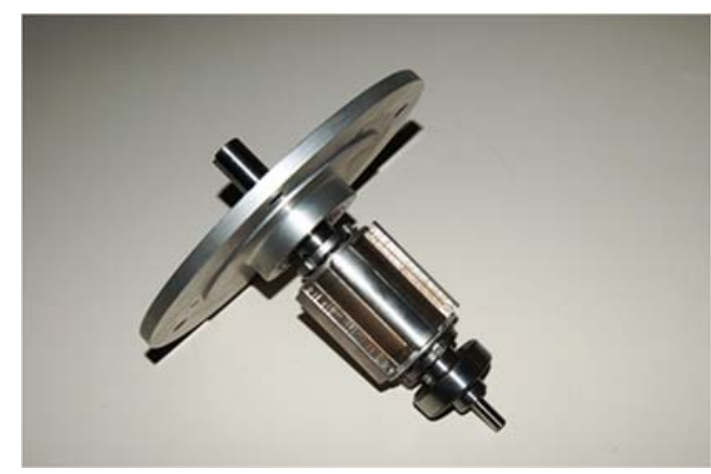

(B)

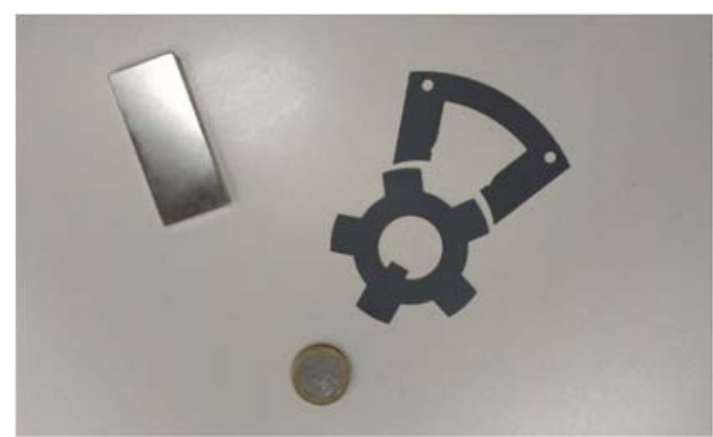

(C)

Fig. 5. Photographs of the stator (A), of the rotor (B) and a detail of the permanent and stator/rotor laminations of single layer hybrid reluctance motor prototype.

The proposed hybrid reluctance motor has been built, figures $5 \mathrm{~A}, 5 \mathrm{~B}$, and $5 \mathrm{C}$ show photographs of the stator, rotor and details of the permanent magnet and of the laminations of the stator and the rotor. The experimental torque-speed characteristic is shown in Fig. 6. The experimental torque-speed and efficiency-speed characteristics are depicted in Fig. 7, turn-on angle $\theta_{\mathrm{ON}}=4^{\circ}$ and turn off angle $\theta_{\mathrm{OFF}}=28^{\circ}$. It is important to note that efficiency is the global efficiency (hybrid reluctance motor efficiency multiplied by the efficiency of power electronic converter). From the tests carried out the motor can be rated at $1100 \mathrm{~W}$ and due to their efficiency levels can be classified as an IE4 motor.

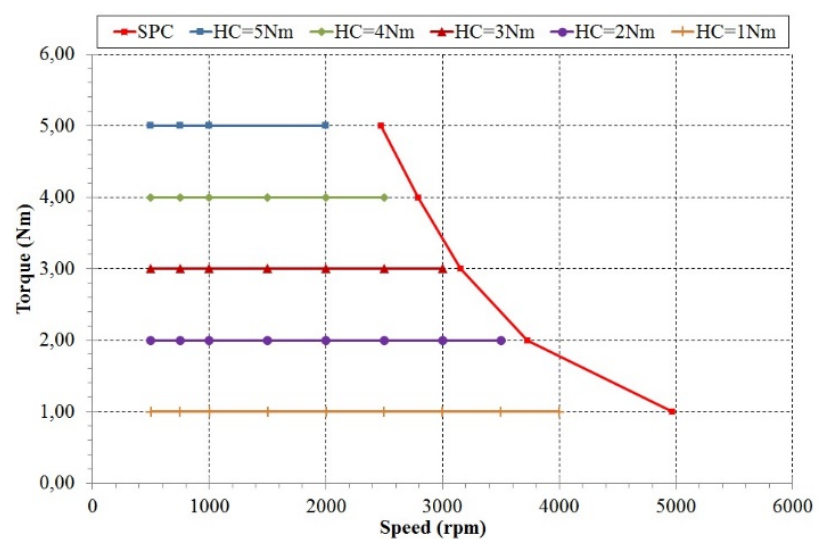

Fig. 6. Experimental torque-speed characteristics for different control strategies (SPC: single pulse control; HC: Hysteresis control).

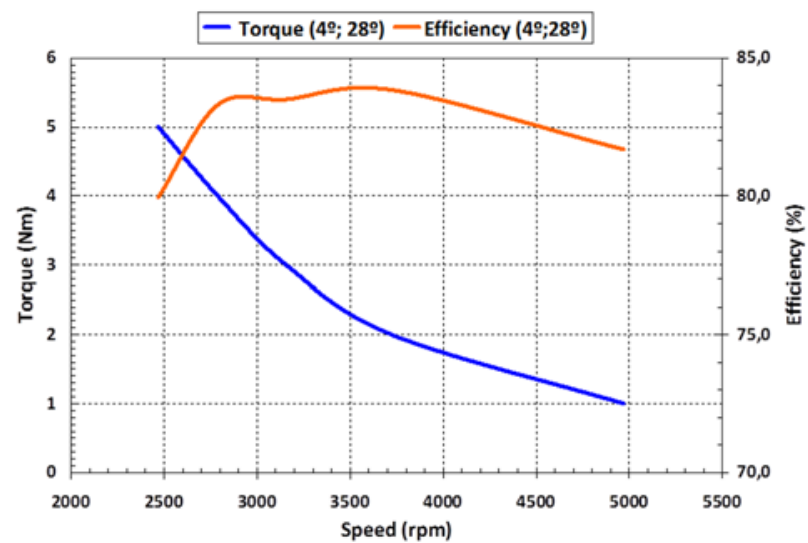

Fig. 7. Torque-speed and efficiency speed characteristics (single pulse control).

Despite these advantages due to the distribution of the phase windings of the considered single layer rotary hybrid reluctance motor, unilateral attractive forces between stator and rotor appear producing vibrations and magnetic noise. This can be avoided using single layer three phase hybrid reluctance motors with two electromagnets with permanent magnets per phase, multiplicity $\mathrm{k}=2$, and ten rotor poles. The phases are formed by two opposite electromagnets with permanent magnets with the coils connected in series. The field lines distribution in the aligned position of this motor configuration with one phase excited is shown in Fig. 8, in which the symmetrical disposition of the flux lines can be clearly observed.

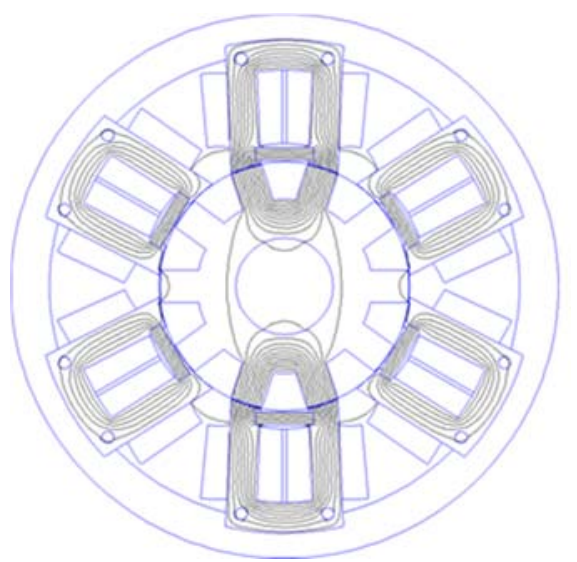

Fig. 8. Field lines distribution in aligned position of a three phase hybrid reluctance motor, multiplycity $\mathrm{k}=2$, with 6 electromagnets with permanet magnets and 10 rotor poles.

\section{B. Single layer rotary hybrid reluctance generator}

The single layer three phase machine, with three electromagnets with magnets, 6 stator poles and 5 rotor poles has been moved by a primary motor, a D.C. machine, and has worked as a generator. Fig. 9 shows the equivalent circuit per phase, Fig. 10 displays the simulation results obtained using Matlab-Simulink and Fig. 11 shows the experimental results. 


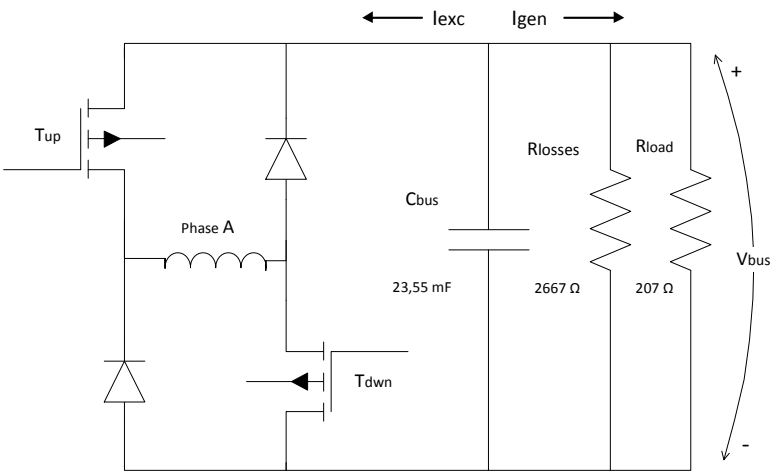

Fig. 9. Equivalent circuit per phase of the hybrid reluctance generator $6 / 5$.
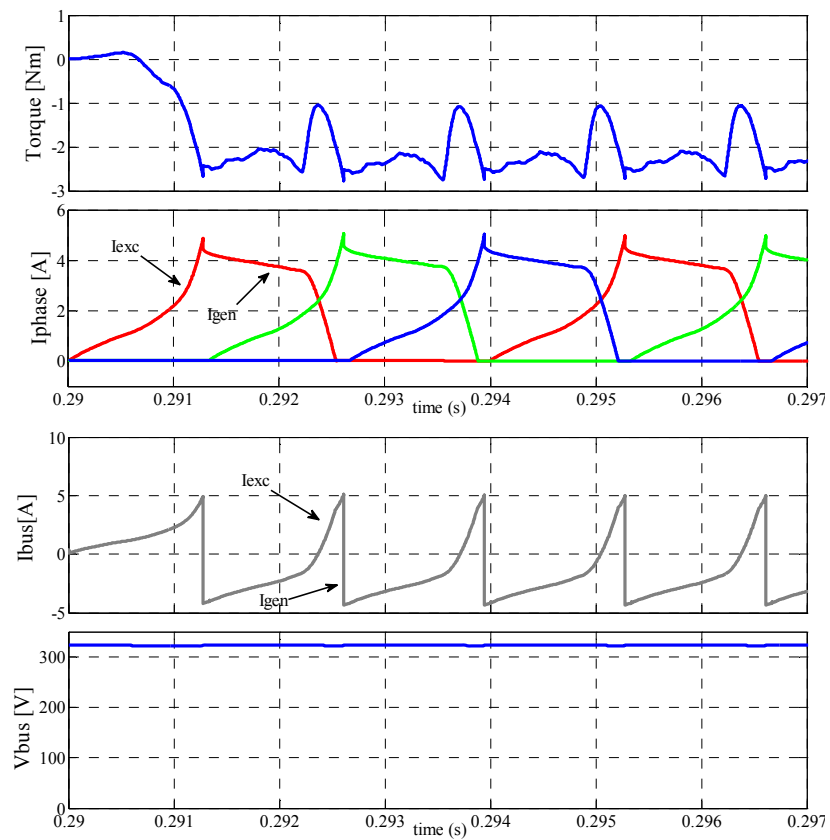

Fig. 10. Simulated waveforms of torque, phase current, bus current and bus voltage and voltage for the single layer rotary hybrid reluctance generator obtained using Matlab-Simulink .

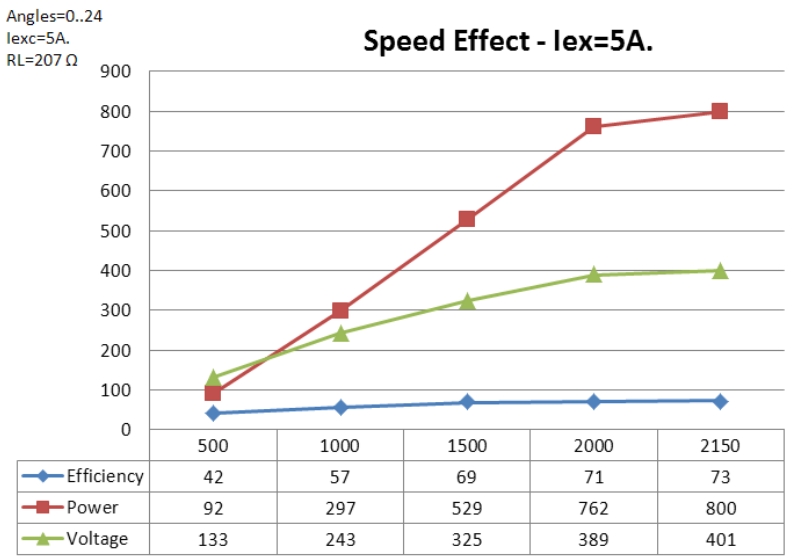

Fig. 11. Experimental results for single layer hybrid reluctance generator showing the evolution of efficiency, power and voltage at different speeds.

\section{Multilayer or Multistack Rotary Hybrid Reluctance Machines}

In multilayer rotary hybrid reluctance machines the number of layers equals de number of phases. The number of electromagnets with permanent magnets, $\mathrm{Np}$, the number of stator poles, Ns, and the number of rotor poles, $N_{R}$ have to meet the following rules:

$$
\begin{gathered}
N_{p}=k \cdot m(10) \\
N_{s}=2 \cdot k \cdot m(11) \\
N_{R}=N_{s}
\end{gathered}
$$

The stator poles and the rotor poles of the first layer have a nil positional offset between them, but the poles of the consecutive parallel layers have a positional offset, $\theta_{s}$, according to:

$$
\theta_{S}=\frac{360^{\circ}}{m \cdot N_{R}}
$$

The angles $\gamma, \alpha, \delta$ are computed using the equations (4), (5) and (6) respectively

In Fig.12 a perspective view of a multilayer hybrid reluctance motor with 3 layer 6 stator poles 6 rotor poles is shown.

A four phase 8 poles multilayer hybrid reluctance motor which main parameters are listed in table III, has been simulated. In Fig. 13 a finite element simulation in the aligned position is shown. In Fig.14 it can be seen the Matlab-Simulink simulation of the complete drive including motor, power electronic converter and control. This motor can be rated $22 \mathrm{~kW}$ with efficiency above $93 \%$.

Table III. Main parameters of the proposed HRM

\begin{tabular}{|c|c|c|c|c|c|c|c|c|}
\hline $\mathrm{k}$ & $\mathrm{m}$ & $\mathrm{N}_{\mathrm{P}}$ & $\mathrm{N}_{\mathrm{S}}$ & $\mathrm{N}_{\mathrm{R}}$ & $\alpha$ & $\gamma$ & $\delta$ & $\theta \mathrm{s}$ \\
\hline 1 & 4 & 4 & 8 & 8 & $45^{\circ}$ & $90^{\circ}$ & $45^{\circ}$ & $11.25^{\circ}$ \\
\hline
\end{tabular}

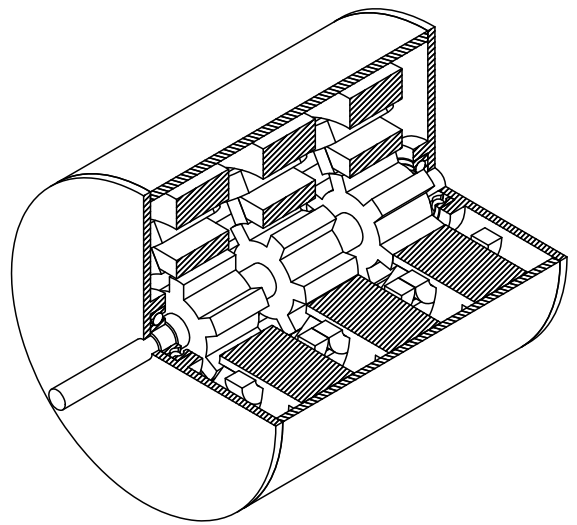

Fig. 12. Perspective view of a three phase 6 stator poles 6 rotor poles multilayer hybrid reluctance machine. 


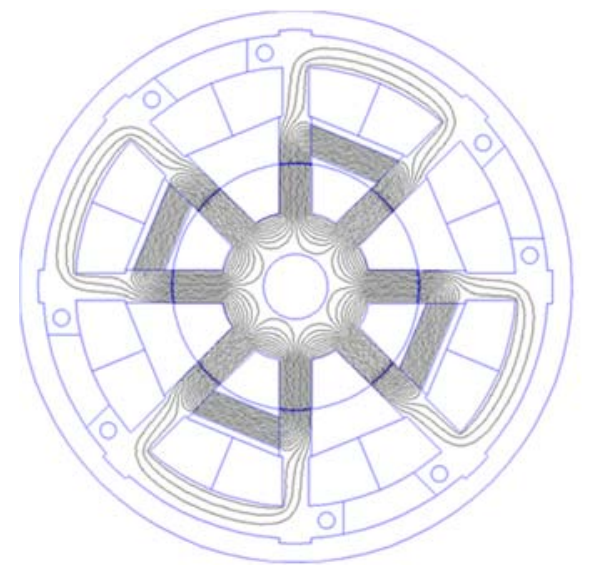

Fig. 13. Distribution of the field lines (obtained by finite elements) in aligned position of a four phase multilayer hybrid reluctance motor.
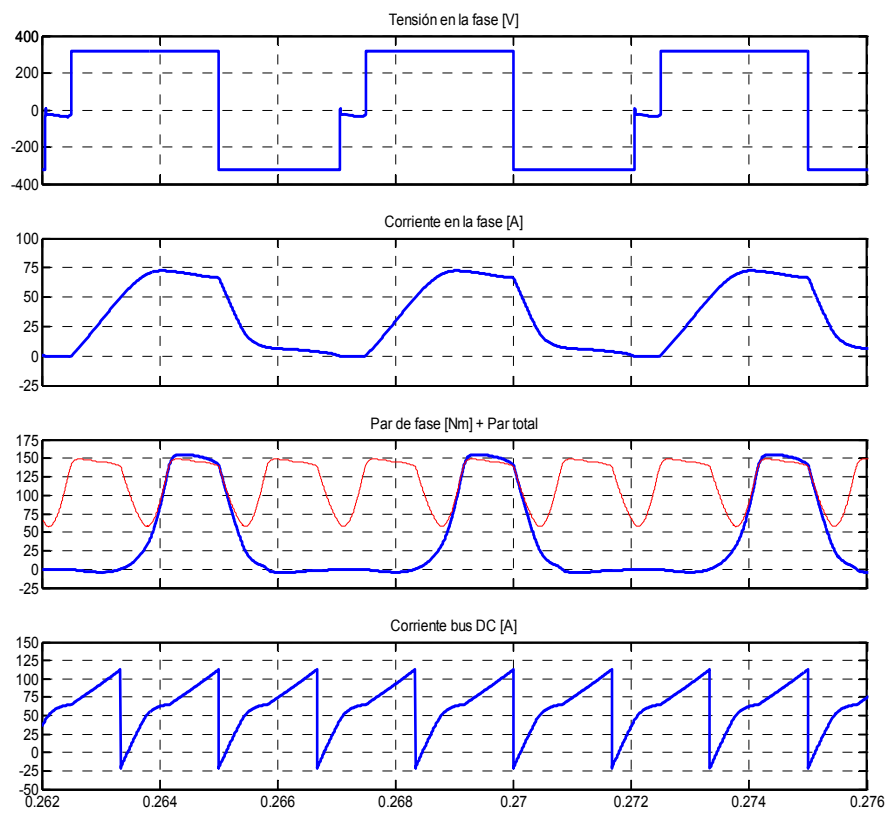

Fig. 14. Phase voltage, phase current, phase torque (blue), total torque (red) and D,C, bus current waveforms. VD.C. bus voltage $320 \mathrm{~V}$, with firing angles: $\theta_{\mathrm{ON}}=2^{\circ}, \theta_{\mathrm{OFF}}=24^{\circ}$.

\section{Linear Hybrid Reluctance Machine}

In linear hybrid reluctance machines the U-shaped electromagnets with permanent magnet are fixed while the translator or mover is composed by salient poles. Fig. 15 shows the single side alternative and Fig. 16 the double-side option that has the advantage that does not produce a net normal force on the translator. A simple low cost two-phase linear hybrid reluctance actuator able to produce linear forces in the range of 200 to $300 \mathrm{~N}$ at a speed of $0.15 \mathrm{~m} / \mathrm{s}$, Fig. 17, has been proposed [12]. Two phase actuator is a good choice if, as in this case, has to start in predetermined positions and force ripple is not a drawback, however a three-phase actuator should be considered in any other circumstance. Simulation of the hybrid reluctance actuator considering the electromagnetic actuator, the electronic power converter and the control is implemented using Matlab-Simulink coupled with the results obtained of a previous finite element analysis. Fig. 18 shows the waveforms of phase voltage, phase current, phase force, total force and DC bus current for a regulated current of 5 $\mathrm{A}$ and a speed of $0.15 \mathrm{~m} / \mathrm{s}$. The turn-on position, $\mathrm{x}_{\mathrm{ON}}=0$ $\mathrm{mm}$, coincides with the non-aligned position of the poles of the stator and the mover and a turn-off position, $\mathrm{x}_{\mathrm{OFF}}=$ $25 \mathrm{~mm}$, in which the poles of the stator and the mover are aligned.

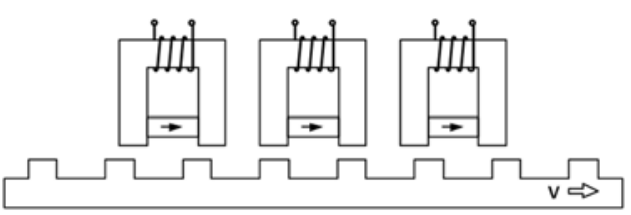

Fig. 15. Single side linear hybrid reluctance machine.

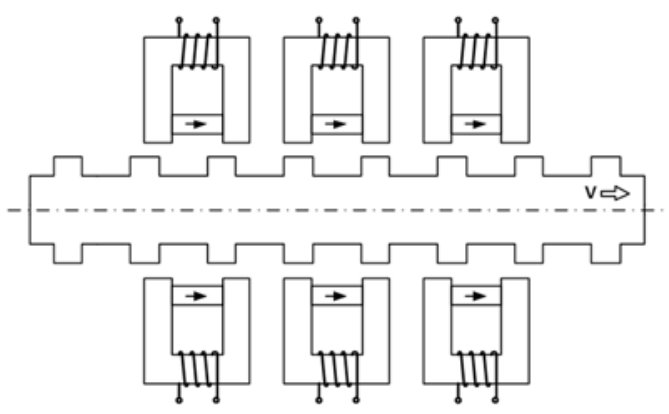

Fig. 16. Double-sided linear hybrid machine.

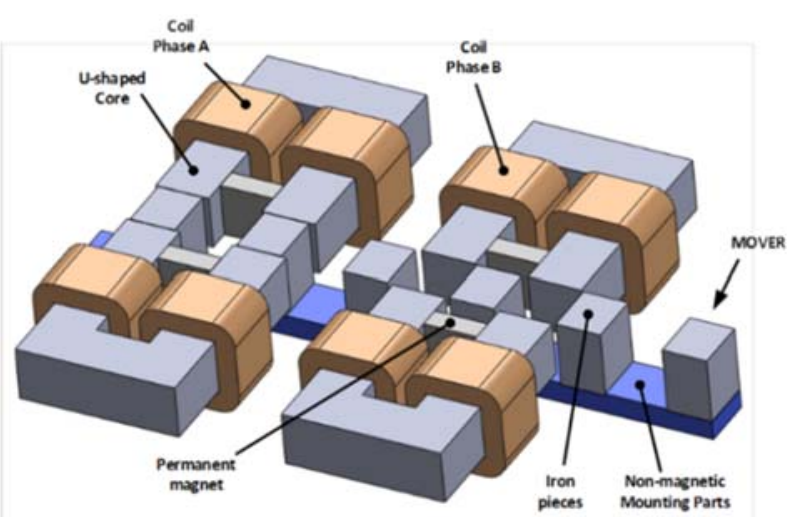

Fig. 17. View of the two phase linear hybrid reluctance actuator.

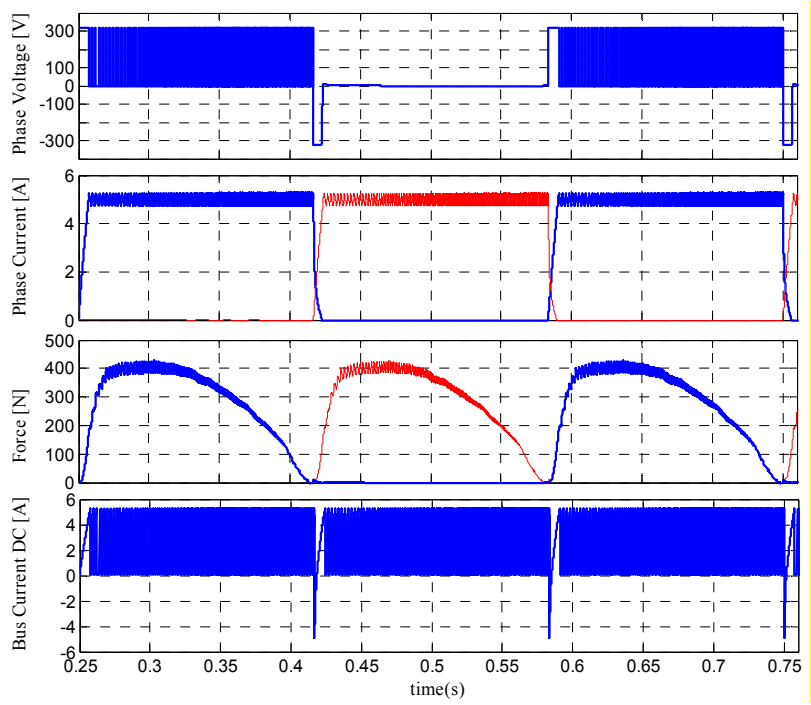

Fig. 18. Waveforms of phase voltage, phase current, force and D.C. bus current at $0.15 \mathrm{~m} / \mathrm{s}$. 


\section{Conclusion}

A new class of hybrid reluctance machine has been presented. They are composed for a combination of Ushaped electromagnets with permanents magnets placed between their arms in the fixed part and with a structure with salient poles in the moving part (without coils, permanent magnets or bars). They can be designed to build different types of rotary or linear electric motors and generators with outstanding performances. In this paper have been described different types of these hybrid reluctance machines: single layer rotary motors rotor, the single layer rotary generator, the multilayer rotary motor and the linear motor. Simulations and experimental results have proved the capabilities of this novel class of hybrid electric machines.

\section{Acknowledgement}

This work was supported by Fundació Equilibri. The authors wish to thank Mr. Francesc Folguera, President of Fundació Equilibri, for his continuous encouragement and the scientific team of RAC Technologies S.A. for the concepts they contributed since 2010 which were the germinal work for this publication. They also would like to thank IMA S.L, for providing the permanent magnets used in this research.

\section{References}

[1] Y. Liao, F. Liang and T. A. Lipo. "A Novel Permanent Magnet Motor with Doubly Salient Structure". IEEE Transactions on Industry Applications, Vol. 31, No. 5. September-October 1995, pp.1069-1078
[2] Y. Amara, E. Hoang, M. Gabsi, M. Lécrivain and S. Allano "Design and comparison of different flux-switch synchronous machines for an aircraft oil breather application" Euro. Trans. Electr. Power 2005; 15, pp. $497-$ 511

[3] J.R. Hendershot. "Polyphase electronically commutated reluctance motor". Patent US 4883999, November 28, 1989.

[4] C.J. Hanckok and J.R. Hendershot. "Electronically commutated reluctance motor". Patent US 5015903, May $14,1991$.

[5] C.S. Garron. "Electric motor with permanent magnet combined with electromagnets". Patent US 4132911, January 2, 1979.

[6] J.M. Bailey, I. Alexeff, W.H. Kreidl. "Polarized electromagnetic device". Patent US 4479103, October 23, 1984.

[7] O. Rolando Avila. "Hybrid electric reluctance motor". Patent US 7615905 B2, November 10, 2009.

[8] K. Nakamura, K. Murota, O. Ichinokura. "Characteristics of a novel switched reluctance motor having magnets between the stator pole-tips". EPE 2007, pp. 1-5

[9] P. Andrada, O. Rolando Avila, B. Blanqué, E. Martínez, M. Torrent, J. Adelantado. Hybrid electric reluctance machine. European Patent Application EP 2693613 A1.

[10] P. Andrada, B. Blanqué, E. Martínez, M. Torrent. "Novel type of hybrid reluctance motor drive". IEEE Transactions on Industrial Electronics. Vol.61, No 8, August 2014, pp. 4337-4345

[11] P. Andrada, B. Blanqué, E. Martínez, M. Torrent. "New Hybrid Reluctance Motor Drive". 20th International Conference on Electrical Machines. ICEM 2012. Marsella, France, 2-5 September 2012, pp. 2689-2694

[12] P. Andrada, B. Blanqué, E. Martínez, M. Torrent, J. GarciaAmorós, J.I Perat. "New linear hybrid reluctance actuator". 21th International Conference on Electrical Machines. ICEM 2014. Berlin, Germany, 2-5 September 2014, pp.585590. 